closely with the figure for institutional cases. In the direct line there was a neuropathic taint in $68 \%$. In the direct line psychoses and nervous disorders were more frequent in extra-mural cases; alcoholism, psychopathic personality and suicide were less frequent. The author considers that the very mild and brief cases of manicdepressive depression, frequently not recognized as such, are in their nature identical with the classic institutional cases.

G. W. T. H. Fleming.

\title{
Mental and Emotional Phenomena of Some Psychoses in their Relation to Blood-pressure; Diagnostic and Prognostic Significance of the Latter. (Fourn. of Nerv. and Ment. Dis., October, 1930.) Gordon, $A$.
}

The author investigated 37 cases of psychosis. All gave a lowering of blood-pressure half an hour after the injection of 200 grm. of milk. There was no alteration in a control group of 15 normal individuals and 7 obsessional cases. In the manic cases the difference between the terminal ascent and the original bloodpressure was smaller than in the depressives. There appeared to be a relationship between these differences and the duration of each phase of a manic-depressive psychosis; the smaller the difference the longer the manic phase lasted, and the greater the difference the longer the depressive phase lasted. In the confusional cases there was a striking similarity to the depressive phases of the manic-depressive psychosis. In the dementia præcox group, during the gradual descent of blood-pressure there was a considerable abatement in restlessness, especially in the automatic and stereotyped movements. In the cases of anxiety neurosis the lowering of the blood-pressure was accompanied by an amelioration of the main symptoms.

G. W. T. H. Fleming.

Post-Encephalitic Parkinsonism with Psychosis. (Fourn. of Nerv. and Ment. Dis., September, 1930.) Alpers, B. A.

The author thinks that the number of cases of post-encephalitic Parkinsonism which develop a psychosis is small. He describes three cases in his own practice which had similar mental features. All presented hallucinations, chiefly auditory but sometimes visual. There were few other mental disturbances. Hallucinations have not often been reported in the psychosis complicating Parkinsonism. G. W. T. H. Fleming.

Personality Factors in Alcoholism. (Arch. of Neur. and Psychiat., Fuly, 1930.) Hart, $H$. $H$.

The author examined 30 cases at the Blythwood Sanatorium. Most of the patients were typically American; there were no Jews. In all cases there was present a constitutional instability, with parental discord or alcoholism, and lack of discipline and sensible direction in the environment of childhood. Alcohol provides its own Nemesis. Alcoholism is an emotional and moral problem. The treatment, so far as it is possible, resolves itself into building

LXXVII. 
up self-respect, organizing good habits and a feeling of adequacy, rendering it not only possible but attractive to attain a level of mature responsibility-truly a stupendous task.

G. W. T. H. Fleming.

New York Narcotic Drug Survey. (Med.-Legal Fourn., March-April, 1930.) Herzog, $A$. $W$.

The case-histories of 433 men and II 7 women are analysed. Physical pain and mental stress were the primary causes in $13 \%$, and bad associations in $24 \%$. The vast majority of the addicts were of the white races. Married and single persons were represented in almost equal proportions. Heroin addiction comprised more than $59 \%$ of the cases. The majority ranged from 21 to 35 years of age. The average addict purchases from 4 to 25 shillingsworth of drug daily. The method of gradual reduction was applied in all cases, the prescribed period of treatment being three weeks.

\section{Hamblin Smith.}

The Possible Liability of Physicians in Cases of Attempted Suicide. (Med.-Legal fourn., March-April, 1930.) Herzog, $A$. W.

If a sane man is attempting suicide, would another person who interfered be guilty of a technical assault, or be civilly liable for any injuries which the would-be suicide might sustain? The question appears to depend upon whether an attempt at suicide is an offence under the laws of the particular jurisdiction under which it occurred. If it is not an offence, a physician, or any other person who interfered, would be criminally and civilly liable.

M. Hamblin Smith.

Partial Insanity and Criminal Intent. (Med.-Legal Fourn., MayAugust, 1930.) Weihofen, $H$.

The New York Court of Appeals has recently laid it down that "feebleness of mind or will, not so extreme as to justify a finding that the defendant is irresponsible, may properly be considered in determining whether a homicide has been committed with a deliberate and premeditated design to kill, and thus may be effective to reduce the grade of the offence." If generally adopted, this dictum would revolutionize the legal system. It would have, in practice, to be combined with arrangements for the treatment as well as the punishment of "partially insane" offenders, and such treatment would have to be continued after the expiration of the formal sentence of imprisonment.

M. Hamblin Smith.

\section{Pathology.}

The Physiopathological Significance of the Meningeal Permeability. (Amer. Fourn. Psychiat., September, 1930.) Katzenelbogen, $S$.

"Meningeal permeability" is selective towards substances introduced into the general circulation; there is no obstacle to 